\title{
LACTANTIUS: 'N VERKENNING VAN 'N VROEG-CHRISTELIKE DENKER SE LEWENS- WÊRELDBESKOULIKE DENKE
}

\section{Die agtergrond}

Lactantius is teen omstreeks 250 n.c. in Africa Proconsularis gebore, en het die gebruiklike klassieke opvoeding by sy leermeester Arnobius, wie se werke "belangriker is weens die informasie oor die heidense godsdiens as oor die Christelike standpunt wat daarin gestel is" (Coetzee, 1954:135), ontvang. Hoewel "Laktanz in seinen erhaltenen Schriften mit autobiographischer Angaben ausserordentlich zurückhaltend" (Gerhardt 1924:1) is, kan uit Hieronymus se De viris illustribus 80 en sy Chron. ab Abr. 2333 (317 n.C.) afgelei word dat hy uitmuntende gawes gehad het. $\mathrm{Hy}$ is trouens as die vir omnium suo tempore eloquentissimus beskou en gerespekteer as 'n student wat deeglike kennis van die klassieke lewe en ideale gehad het. Die gemak waarmee hy opvallend uit sy geheue uit 'n wye reeks klassieke meesters aanhaal, getuig genoegsaam hiervan, (vergelyk Dammig, 1957:9 waar hy Lactantius se "stauenswerten Belesenheit" vermeld), maar sy styl vind die nouste aansluiting by die gepoleerde styl van Cicero, sodat Hieronymus tereg kon opmerk dat sy styl "quasi quidam fluvius eloquentiae Tullianae" (Ep. 58 ad Paulinum, CSEL 54:539) is, en dat hy daarom met reg as die Cicero Christianus beskou kan word. (Vgl. Hieronymus: eandem ob causam eo honore affectus fuit ut a posteris cognominatus sit Cicero Christianus.) Pico de la Mirandola toon dieselfde onverhole bewondering vir sy styl wanneer hy Lactantius selfs bo Cicero wil stel: quis apud nos non videat esse Ciceronem, sed Christianum, hoc est aliquem qui eum ad lineam unguemque expresserit? Quis enim non advertit Lactantium aequasse ipsum et forte praecelluisse in eloquendo? (Opera, 1573:21). Dit is daarom nie verbasend dat Diocletianus hom teen omstreeks 290 na Nikomedië in Bitinië ontbied het om daar onderrig in die retoriek te gee nie. Diocletianus se ideaal was tewens om van Nikomedië nie alleen die administratiewe hoofstad van die Oos-Romeinse Ryk te maak nie, maar ook die belangrike kultuursentrum. (Monceaux, 1905:290 "il voulat faire de Nicomädie un Autre Rome.") Die Romeinse Ryk was aan die wankel. Op godsdienstige gebied is die klassieke pantheon verontmitologiseer en onder die aanslae van die Hermetiese godekritiek het dit vervlak sodat weinig anders as formalisme oorgebly het. Die gebruiklike toevlugsoord, die filosofie in al sy vertakkings en strominge, het 
weinig of geen bevrediging gebied nie. Die misteriekultusse het onder die omstandighede welig geblom, en vir die uitbreiding van die Christendom groot gevaar ingehou. Wrede vervolging van die Christene, daardie tertium genus en natio lucifuga, was aan die orde van die dag. Tydens Lactantius se lewe is die edicta van Decius, Valerianus (258), en Aureiianus (270 en 275) afgekondig. Op 23 Februarie 303 word 'n edik van Diocletianus wat die volgende dag met 'n verdere edik aangevul is, en daarop gemik was om die Christendom heeltemal uit te wis, uitgevaardig. (Jones, 1964:71; vgl ook Frend, 1965:).

Dessau merk tereg op dat "die Veschiedenheit der Sprachen und der Literatur ein Kluft zwischen dem Westen und dem Osten (bildet) die sich niemals ganz schloss"' (Dessau, 1930:592). So het Lactantius dit ook ervaar. Hy is deur die Griekse levitas ontnugter, want prostituerunt libidini iuventutis, en dit is vir hom nie verbasend dat die Grieke qui res levissimas pro maximis semper habuerunt (Divinae Institutiones 1.18.7) verantwoordelik was vir al die sondes waarm die mens verval het nie ( $s i$ $a b$ hac gente universa flagitia manarunt) - (D.I.1.20.15).

Dit was egter veral die wrede vervolging van die Christene van 303 n.C. wat vir hom 'n intens louterende ervaring was. Hy beskryf verskeie gruweldade teen die Christene: die vernietiging van die kerk in Nikomedië (D.I. 5.2.2), die foltering en verbranding van 'n Christen wat genoeg durf aan die dag kon lê om die edik van Diocletianus af te ruk en stukkend te breek (D.I. 5 ) en die blydskap van 'n owerste wanneer dit vir hom lyk asof 'n Christen wat twee jaar lank sy foltering moedig weerstaan het, uiteindelik swig. (D.I. 5.11.15). God se wraak teen die vervolgers is tewens die tema van sy werk De mortibus persecutorum.

\section{Die Divinae Institutiones}

Lactantius se opus magnum is sy Divinae Institutiones. In 'n werk wat hieraan voorafgaan, sy $D e$ opificio $D e i$, maak hy sy voorneme bekend om ' $n$ integra disputatio teen die filosowe te voer. Sy opus magnum is gevolg deur die De ira Dei. Nou is dit aantreklik om dit saam met Monceaux as 'n soort trilogie te beskou waarin "le de opificio Dei est comme un appendice" (1905:307). Daar is egter geen gronde waarop so 'n beskouing gebou kan word nie. 
Die Diviniae Institutiones bestaan uit sewe boeke. Lactantius heg byna magiese waarde aan die getal sewe. Dit is vir hom 'n numerus expletus et perfectus. Hy bou trouens 'n uitgebreide chiliasme rondom hierdie getal. (Vgl. Fabréga, 1974:146).

Die sewe boeke dra elk sy eie titel soos volg: De falsa religione; De origine erroris; De falsa sapientia. Hierdie drie kan beskou word as die destruktiewe deel (die pars destruens of principia) van sy diatribe (wat "in ihrer Anlage ein fingierter Dialog mit einem anonymen Gesprächspartner" is (Marrou in RAC 3 kol. 998). Hierop volg: De vera sapientia et religione; De iustitia; De vero cultu. Hierdie konstruktiewe deel (die pars adstruens) word afgesluit met die De vita beata. Met die eerste oogopslag behoort dit duidelik te wees dat die werk versigtig beplan is - daar is duidelike blyke van retoriese consilium en ratio. Die volgorde waarin die boeke voorkom, dui op 'n progressief stygende apologie waarin Lactantius die eerste ses boeke as fundamenta beskou en die laaste as die corona of divinum praemium beatitudinis perpetuae. Dit kom duidelik in die prooemium van die sewende boek na vore waar hy aan die hand van enkele vrae die temas wat in die voorafgaande boeke behandel is, kortliks onder die leser se aandag bring:

- Quid prodest aut falsis religionibus liberari (die tema van boek 1 en 2) aut intellegere veram? (boek 4).

- Quid aut vanitatem falsae sapientiae pervidere (boek 3) aut quae sit vera cognoscere? (boek 4).

- Quid prodest caelestem illam iustitiam defendere? (boek 5).

- Quid cum magnis difficultatibus cultum Dei tenere (boek 6) quae est summa virtus.

met die slotsom opgesluit in die voltooiing van die voorwaardelike sin:

nisi eam (sc. summa virtus - cultum Dei tenere) divinum praemium beatitudinis perpetuae subsequatur. (D.I. 7.1.3).

Hierdie struktuur is ongetwyfeld gemotiveer uit die Openbaringsboek waarin die getal 7 dikwels voorkom, en waarop Lactantius "im Rahmen einer geschlossenen Eschatologie seine chiliastische Lehre als Vertreter einer breiten kirchlichen Tradition in Osten und Westen entfaltet" (Fabré- 
ga, 1974:146). Teen hierdie agtergrond is dit eweneens duidelik dat Stevenson se kontensie "That Lactantius prompted by a pagan literary offensive against Christianity, began to write Tracts for the Times" (Stevenson, Stud. Patr. 1.1.:661 e.v.) onaanvaarbaar is.

\section{Lactantius se lewens- en wêreldbeskouing}

\subsection{Sy doel met en die aanleiding tot die skrywe van die Divinae} Institutiones

Die direkte prikkel tot die skrywe van die Divinae Institutiones was dat Lactantius twee manne moes aanhoor qui iacenti atque abiectae veritate nescio utrum superbius an inportunius insultarent (D.I. 5.2.2). Een hiervan was 'n filosoof (Porphyrius?) wat nie naastenby in die praktyk die beginsels wat hy in die teorie verkondig het, uitgeleef het nie. So 'n lewenswyse druis trouens lynreg teen Lactantius se opvatting in dat die mens se strewe nie net bloot na die waarheid moet wees nie, maar dat hy die waarheid ook moet uitleef: bonum est autem recta et honesta praecipere, sed nisi et facias, mendacium est, et est incongruens atque ineptum non in pectore sed in labris habere bonitatem (D.I. 3.16.4). Die tweede was 'n man e numero iudicum wat as auctor faciendae persecutionis 'n leidende rol in die vervolging van die Christene gespeel het. Hy verwys hier waarskynlik na ene Hierocles wat in twee boeke onder die titel Philalethes erken het dat Christus deur die Jode gekruisig is, maar verklaar dat Petrus, Paulus en die ander apostels slinkse leuens uitgedink het om Christus se lewe en opstanding aanskoulik voor te stel tamquam fallaciae seminatores (D.I. 5.2.17). Dit is nie onwaarskynlik dat die skrywer self Christen was nie, maar dat hy voor die aanslae van die vervolging geswig en sy geloof geloën het.

Lactantius het egter ook 'n verdere doelstelling gehad, naamlik om die Christelike lewens- en wêreldbeskouing met die klem op die etiese te sistematiseer en die heilswaarhede van die Skrif vir ontvanklike heidene en vir nog twyfelende bekeerdes toeganklik te maak. In die lig hiervan is Overlach se opvatting ten volle gegrond. Hy poneer die volgende: "Demnach dürfen wir eine tiefer gehende wissenschaftliche Entfaltung der specifisch christelichen Mysterien, wie sie nur dem gereiften christelichen Leben und Denken verständlich und förderlich ist, von vorm herein nicht erwarten" (Overlach, 1858:11). 


\subsection{Sy metode}

In die exordium van die eerste boek van sy Institusie gee Lactantius 'n aanduiding van sy beplanning: succurrendum esse his erroribus credidi et docti ad veram sapientiam dirigantur et indocti ad veram religionem (D.I. 1.1.7). Daarmee saam skets hy ook die verskil tussen regshandboeke en sy eie godsdienshandboek. Terwyl eersgenoemdes alledaagse regsvraagstukke behandel, is die tema van sy werk hoop, die lewe, saligheid, onsterflikheid en God.

Hoewel Lactantius in besonder in die pars adstruens sy lewensbeskoulike denke weergee, is daar 'n geleidelike oorgang van die pars destruens hierheen. Hierin volg hy die trappe ter verkryging van die waarheid wat hy elders onderskei, naamlik primus gradus est intellegere falsas religiones et abicere inpios cultus humana manu fabricatorum; secundus vero perspicere animo quod unus sit deus summus cuius potestas ac providentia effecerit a principio mundum et gubernet in posterum. Tertius, cognoscere ministrum eius ac nuntium quem legavit in terram quo docente liberati ab errore quo inplicati tenebamur formatique ad veri dei cultum iustitiam disceremus (De ira 2.1 - 2). In hierdie uiteensetting van sy metode is daar dus drie aspekte: kennis van die valse godsdiens (en filosofie), kennis van God, die Skepper en Onderhouer van die heelal, en kennis van Christus en sy verlossingswerk. Ten opsigte van die eerste aspek is dit genoegsaam om hier op te merk dat Lactantius 'n oorstelpende kennis van die klassieke politeisme en filosofie toon en beide suis armis beveg om in die plek daarvan die ware godsdiens en sapientia te stel. Veral in sy analise van die oorsake wat tot hierdie dwalinge gelei het, baan hy die weg vir 'n uitgebreide dualisme waarin hy verklaar dat God die Skepper van alle dinge was - dit is van goed sowel as van kwaad. Geen sprake van 'n sondeval nie! Die machinator omnium bonorum staan teenoor die machinator omnium maiorum (en wie sal Vergilius nie hierin herken nie?) Lig staan teenoor duisternis, hemel teenoor aarde, liggaam teenoor siel, lewe teenoor dood, virtus teenoor vitium en mors aeterna teenoor vita beata. Soos God 'n koninkryk het waar sy engele Hom vereer, het die machinator omnium malorum net so 'n skare om hom in sy kwaad te sterk. Hierdie dualisme kan net verklaar word vanuit sy opvatting dat die mens vrye oordeel (liberum arbitrium) het - 'n vraagstuk wat selfs tydens die Reformasie tot bitter polemiek tussen Calvyn en Pighius van Kampen gelei het. (Vgl. Calvyn, Inst. 1.15; 2.2, 5.) Hierin is hy trouens herout van die Pelagianisme wat die kerk enkele dekades later verskeur het. Verder 
benut Lactantius die geleentheid om 'n demonologie te ontwikkel wat aansluit by klassieke opvattings in verband met demone en bose geeste (vgl. Schneweiss, 1943: passim).

\subsection{Lactantius se Godsbegrip}

Daar bestaan net een almagtige, voorsienige en ewige God wat Homself voor die skepping voortgebring het: consequens est ut quoniam nihil ante illum fuit, ipse ante omnia ex se ipso sit procreatus. Daarom is Hy selfskeppend, selfmakend, sy eie vader en sy eie moeder (D.I. 1.7.13). Sy potestas is so omvangryk dat dit met die verstand nie gegryp en met woorde nie beskryf kan word nie (D.I. 2.8.44). God is soos hy wil wees - talis est qualem esse se voluit - die ewige bron van die volmaakte goed (D.I. 2.8.3) omdat Hy non est aliunde generatus nec ortus ac nativitas eius ex aliqua re altera pendet (D.I. 2.8.44). Hy is ook inpassibilis, immutabilis, incorruptus, beatus et aeternus. Daarby beskrywe hy God as artifex, conditor, factor, parens, princeps et origo rerum, en, vir ons van belang, as pater et dominus. Sy eenheid sentreer in solus et unus, sy ewigheid in aeternus, sy alomteenwoordigheid in ubique praesens, sy volmaaktheid in perfectus et nulli rei subiectus, en sy Godheid in sine sexu aut successione. God beskik oor die lewe en wandel van elke mens en daarom is daar vir die fatum geen plek in sy beskouing nie. Hy betoon genade maar hy kan ook in toorn ontbrand. (De ira 20.1).

As pater betoon God amor teenoor sy kinders en as dominus eis $\mathrm{Hy}$ metus van hulle as sy servi. Wlosok het reeds aangetoon dat hierin 'n presiese analoog van die Romeins-regtelike begrip van die paterfamilias en Gnostiese invloed waargeneem kan word (1960:232). Clementia, diligentia en pietas pas dus by die verhouding van God as Vader tot sy kinders en severitas, disciplina en potestas by die verhouding van God as Dominus tot sy slawe. Hieruit kom hy tot die slotsom: unus igitur colendus est qui potest vere pater nominari: idem etiam dominus sit necesse est quia sicut potest indulgere, ita etiam cohercere. Pater ideo appellandus est quia nobis multa et magna largitur, dominus ideo quia castigandi ac puniendi habet maximam potestatem. (D.I. 4.3.13 - 15). Hy laat geen twyfel daaroor dat sy bron die ius civile is nie: dominum vero eundem esse qui sit pater etiam iuris civilis ratio demonstrat, en soos pater et dominus by God pas, pas filius et servus by die mens. Die oorstelpende orde, die skoonheid en grootsheid van die skepping, sowel as die skepsel skrywe hy aan 'n mirabilis ratio, dit is die divinitas toe, quae gubernat hunc mundum, incredibili beneficentia genus hominum 
sustentat et quasi paterna indulgentia fovet (D.I. 4.3.3; 5.7.1).

\subsection{Die Verbum Dei}

Om die vita beata te verkry het die mens egter 'n Middelaar, 'n mesites tegelyk deus et homo, (D.I.4.25.5) nodig. Voor die skepping van die heelal het God daarom 'n sanctum et incorruptibilem spiritum voortgebring quem filium nuncuparet (D.I. 4.6.1). Onder mense staan Hy as lesus bekend en die woord Christus is ' $n$ aanduiding van sy mag en koningskap: Christus non proprium nomen est sed nuncupatio potestatis et regni (D.I. 4.7.4). Die prima nativitas Christi in die gees het plaasgevind in die ewigheid voor die skepping toe Christus as die Woord van God uit sy mond (Laat daar ....) voortgekom het - voce ac sono ex dei ore processit sicut verbum (D.I. 4.8.8). Die mens se bevatlikheid is egter te beperk om die wyse van sy skepping te peil (D.I. 4.8.6). Die secunda nativitas van Christus in die vlees het in die tyd van Augustus plaasgevind. Omdat die Latynse woord Verbum nie al Christus se eienskappe ten volle uitdruk nie, verkies hy om die Griekse woord logos le gebruik want et sermonem significat et rationem (D.I. 4.9.1). In teenstelling met die engele wat stom is, het Christus ' $n$ spiritus vocalis wat $\mathrm{Hy}$ kon gebruik ad doctrinam dei tradendam (D.I. 4.8.7). Uit die aard van sy Goddelike wese is Christus die perfecta sapientia, die doctor perfectus sapientiae, praeceptor en inluminator (D.I. 4.13.26; 4.14.1; 4.14.14). Die doel van sy sending na die wêreld was ut constitueret aeternum templum deo quod appellatur ecclesia et universas gentes ad religionem veram dei convocaret (D.I. 4.14.1). In die gestalte van die mens moes $\mathrm{Hy}$ as exemplum dien waarvolgens die mens ware geregtigheid, dit is die verering van God, kon bereik (D.I. 4.10.1). Na voltooiing van sy onderwysing moes Hy aan die bose uitgelewer word, die dood op Hom neem, en daaruit verrys (D.I. 4.10.2) om vir die mens die hoop te bied dat hy self ook die dood sal oorwin (spem vincendae mortis offeret). Die woord patientia neem na aanleiding van Christus se lyde 'n baie belangrike plek in Lactantius se werke in omdat die uitnemendste voorbeeld van Christelike lydsaamheid in Christus se lewe waargeneem kan word. God en die Woord van God, dit is Christus, is dus in sy leer 'n unitas. Hy maak wel in die Epitome van sy Institusie melding van die Heilige Gees, maar die Gees en sy werking word nêrens in sy Institusie behandel nie. Hy loën egter nie die bestaan van die Heilige Gees nie. Hieronymus se oordeel spiritus sancti omnino negat substantiam et errore dicit eum vel ad Patrem referri vel ad Filium (Ep. 84.7) lyk daarom nie geregverdig nie. Daar is nogtans geen sprake van die Drie-eenheid by hom nie. Die leer 
van die erfsonde en die verlossende genade van Christus verdwyn in die niet. Onmiskenbaar is Lactantius se opvatting beinvloed deur die Gnostisisme, die Neo-Platonisme en selfs die paganisties filosofiese denke van Cicero (De natura deorum) en Seneca (Epistolae morales en Vita beata).

\subsection{Sy Skeppingsidee}

Lactantius se weergawe van Genesis 1 sien soos volg daar uit: God het eers die hemel geskep quod (caelum) esset sedes ipsius dei conditoris (D.I. 2.9.2) en daarna die wêreld en water. Daarna het God die son, die maan en sterre geskep as onderskeidingstekens van sy habitaculum. Daarteenoor het Hy duisternis en skadu op die aarde, die regnum diaboli, geskep ((D.I. 2.9.3). Hy sit hierdie dualisme ook in die skepping van verskillende dele van die wêreld voort. So is oriens en occidens kensketsend van die stryd tussen die goeie en die kwaad: oriens dui op die lig en op God quia ipse luminis fons et inlustrator est rerum et quod oriri nos faciat ad vitam sempiternam (D.I. 2.9.5). Occidens is simbolies van die duisternis en die skaduryk - quod lumen abscondat, quod tenebras semper inducat et quod homines faciat occidere atque interire peccatis. So is daar in alle dinge, selfs in die seisoene, 'n ewige konflik tussen goed en kwaad. Hieruit lei hy af dat God twee principalia geskep het, naamlik calor et umor. Die een is 'n elementum masculinum en daarom activum, terwyl die ander 'n elementum femininum is en daarom patibile (D.I. 2.9.21). Die mens se siel hoort onder eersgenoemde en sy liggaam onder die vroulike elemente. Hierdie principalia werk enersyds destruktief en andersyds kreatief op mekaar in en deur die wedersydse wisselwerking bring hulle alles volgens die providentia Dei voort en onderhou dit. So het God die wêreld voorberei en met wonderlike middels toegerus om die mens te onderhou.

\subsection{Die mens in die skepping}

God se doel en bestemming met die skepping van die mens gee Lactantius bondig soos volg weer: 
idcirco mundus factus est ut nascamur

ideo nascimur ut adgnoscamus factorem mundi ac nostri ( = notitia dei)

ideo deum adgnoscimus ut (eum) colamus (= cultus dei) ideo colimus ut inmortalitatem pro laborum mercede capiamus (= vita beata)

ideo praemio inmortalitatis adut similes angelis effecti summo ficimur patri ac domino in perpetuum serviamus et simus aeternum deo regnum (D.I. 7.6.1).

God het die heelal dus vir die mens geskep en die mens vir Homself ut esset qui opera eius intellegeret, qui providentiam disponendi, rationem faciendi, virtutem consummandi et sensu admirari et voce proloqui posset: quorum omnium summa haec est: ut deum colat (D.I. 7.5.3). Op die sesde dag het God die mens, liggaam en siel, geskep. Die mens se liggaam bestaan uit die aardse elemente waaroor die duiwel beheer het, terwyl God sy asem in die mens ingeblaas het en sodoende aan hom ' $n$ anima caelestis gegee het. $\mathrm{Na}$ sy liggaam neig die mens dus na vitia, na duisternis en na die duiwel maar na sy siel na virtutes, na die lig en na God (D.I. 2.12.3). Terwyl die liggaam 'n blote hospitium hominis, 'n receptaculum animae is, bestaan die siel uit vuur (D.I. 2.9.22), en daarom is dit incomprehensibilis neque solubilis. Voortplanting van die mens is beperk tot sy liggaam maar die inblaas van 'n spiritus vitalis is deel van die skepping Gods. Die feit dat 'n mens daarna streef om kennis van God op te doen, dat hy regop staan en in staat is tot 'n contemplatio Dei en dat hy sapientia kan verkry, onderskei 'n mens van 'n dier. Die mens wat in hierdie lewe virtutes najaag, word in die lewe hierna daarvoor beloon - nie die loutere genadige sondevergiffenis van God en die soenverdienste van Christus nie, maar die Roomse leer van goeie werke! Soos daar by hom 'n 'jenseitiges' en 'diesseitiges' lewe is, is daar ook twee vorms waarin die dood voorkom. Die eerste is die beëindiging van die liggaamsbestaan, en die tweede is die dood van verdoemde siele na die laaste oordeel. $\mathrm{Na}$ aanleiding hiervan tref Lactantius 'n vergelyking tussen filosowe se en sy opvatting van die Iwee weë (D.I. 6.3.6). Hier volg 'n skematiese weergawe van sy siening: 
vita aeterna

vita condemnata

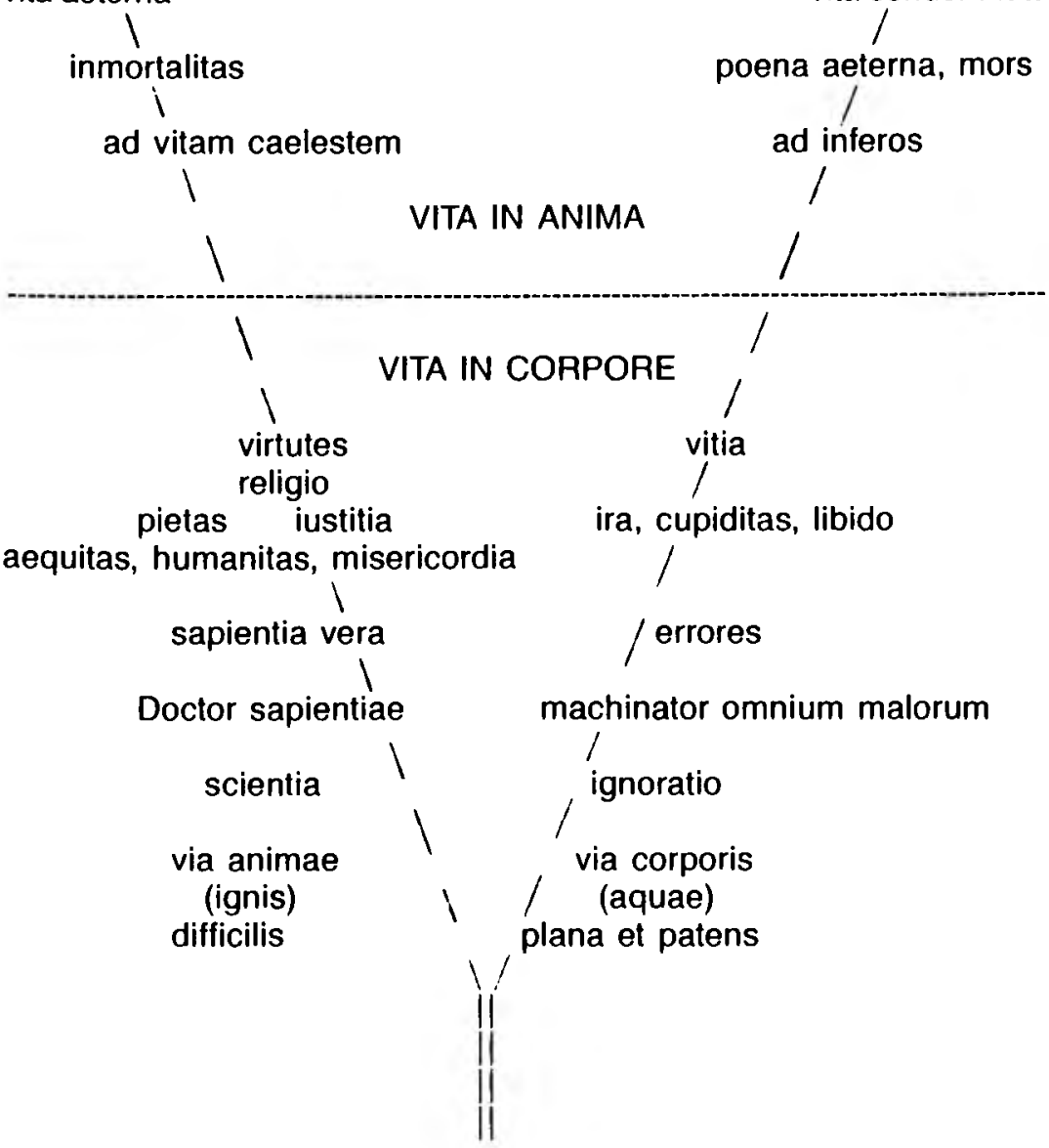

vitae cursum primae adulescentiae

Hierdie skema gee in 'n neutedop Lactantius se lewens- en wêreldbeskouing weer. Tog moet ons hier opmerk dat religio volgens sy opvatting op die interpretasie van die liefdesgebod as liefde teenoor God (pietas) en liefde teenoor die naasle (iustitia) berus. Laasgenoemde sluit aequitas, humanitas en misericordia in. Lactantius is egter nie konsekwent in hierdie onderskeid nie, en dikwels word religio, pietas en iustitia uitruilbaar gebruik (vgl. bv. Ep. 29.5). Dit verklaar ook waarom hy by 
geleentheid religio en dan weer iustitia as die hoogste goed beskryf (D.I. 3.10.1; 7.9.10 en Ep. 29.1). Elk van die deugde wat tot die summum bonum lei, het egter 'n ooreenstemmende ondeug wat tot die summum malum en die ewige dood lei. Die drie bykans sinonieme uitdrukkings: aanbidding van God, najaag van geregtigheid en die beoefening van deug wat tot onsterflikheid lei, het dus ooreenstemmende gebreke wat tot die ewige dood lei. Dit is opvallend dat Lactantius van modelle gebruik maak wat reeds in die Klassieke denke geyk was. Sapientia en sapiens het egter 'n heeltemal andersoortige konnotasie in sy woordeskat as wat dit in die Stoïsynse wysbegeerte gehad het - ongetwyfeld ' $n$ poging om sy nuut verworwe Christianitas op sy oorgeêrfde Romanitas te implanteer. Virtus wat in die Stoisynse leer outonomie gehad het en doel opsig was, vorm by Lactantius een van die trappe in die verkryging van die ewige onsterflikheid maar voer geen outonomie daaroor nie. Scientia cum ignoratione coniuncta vorm die basis van die mens se kenvermoë, en as die kennis van God deur die openbaring verlig is, gaan dit oor in sapientia vera wat die klassieke philosophia in alle opsigte vervang. Dieselfde semantiese verskuiwing van betekenis kan waargeneem word in die geval van pietas, humanitas, misericordia en dergelike begrippe.

\section{Samevatting}

Om af te sluit: hoewel Lactantius se lewens- en wêreldbeskouing vol gebreke, leengoed uit paganistiese bodem en verkeerde Skrifuitleg is, was hy in Brandt se woorde 'ein ehrenhafter Charakter, seine Sitllichkeit und Frömmigkeit ist ernst und wahr; er besitzt eine Fülle von Kenntnissen manifachster Art; Geist und Witz sprudeln reichlich bei inn hervor. Keine Kirchenschrifsteller, und gewis wenige Profanschrifsteller sind von eintönigen Wesen und Pedantrie weiter entfernt als er, und seine Kunst der Darstellung müssen selbst seine Gegner, an denen es ihm auch nicht gefehlt hat, anerkennen.' (NJb. fr Ph. und P Dd., 37(1), 1891, p. 254). Tot sy krediet moet gereken word dat hy die Christelike Institusiewese ingelei het - sy didaktiese grondslae verskil trouens weinig of niks van Calvyn s'n nie want albei stel hulle ten doel rudimenta quaedam tradere, quibus formarentur ad veram pietatem, qui aliquo religionis studio tanguntur (Inst. Chr. Rel.1.1). Ons kan verder daarvan verseker wees dat Lactantius se Institusie 'n bydrae gelewer het om die lydende kerk 'n strydende kerk, en die strydende kerk 'n triomferende kerk te maak. 


\section{Bibliografie}

BARDENHEWER, O. 1962. Geschichte der altkirchlichen Literatur, 2 vols., Darmstadt:Wissenschaftige Buchgesselshaft.

BRANDT, S. 1891. Ueber das Leben des Laktantius, Sitz.ber. der K. Akademie der Wiss. in Wien, Phil.-hist. Kl., 120(5).

COETZEE, W.N. 1954. Die Christendom en die Klassieke. Koers 22:131 - 150 (Inougurele rede).

DAMMIG, J. 1957. Die D.I. des Laktanz und ihre Epitome, Diss., München.

DE LABRIOLLE, P. 1968. The history and literature of Latin Christianity, London: Routledge \& Kegan Paul, 1968.

EGGER, C.: 1953. De C.F.Lactantio Cicerone Christiano, Latinitas. 1,38 - 53.

DESSAU, H. 1930. Geschichte der römischen Kaiserzeit, Berlin, Weidmann,

FREND, W.H.C. 1965. Martyrdom and persecution in the early church. Oxford: OCP.

FABRÉGA, A. 1974. kDie Chiliasmus des Lactantius. J6AC 17, 126-146. GERHARDT, M. 1924. Das Leben und die Schriften des Lactantius, RauHaus, Hamburg.

HARNACK, A. 1958. Geschichte der altchristlichen Literatur. Heinrichs: Leipzig, 1958.

JONES. A.H.M. 1964. The latter Roman Empire 284 - 602: a social, economic and administrative survey. vol. 1. Oxford: Blackwell.

Marron, H.J. 1956. A History of education in antiquity. New York: Sheed \& Ward.

MONCEAUX, P. 1905. Histoire littëraire de l'Afrique chrëtienne. Tome troisiëme: Paris.

OVERLACH, E. 1858. Die Theologie des Lactantius, Gymn. Progr. 4, Schwerin.

PICHON, R. 1901. Lactance, Paris: Librairie Hachette.

Schneweiss, E. 1943. Angels and demons according to Lactantius, Washington.

STEVENSON, J. S.j. The life and literary activity of Lactantius, Stud. Patr. 1,1,661 - 677 .

THOMAS, L. 1959. Die sapientia als Schlüsselbegriff zu den D.I. des Laktanz. Freiburg: Diss.

WLOSOK, A. 1960. Laktanz und die philosnphische Gnosis. Heidelberg: Carl Winters. 